Pesq. Vet. Bras. 38(4):573-578, abril 2018

\title{
Parâmetros de qualidade do leite bovino em propriedades de agricultura familiar ${ }^{1}$
}

\author{
Leandro T. Jamas ${ }^{2}$, Anelise Salina ${ }^{2}$ Rodolfo Rossi ${ }^{3}$, \\ Benedito D. Menozzi² e Hélio Langoni ${ }^{4 *}$
}

\begin{abstract}
Jamas L.T., Salina A., Rossi R., Menozzi B.D. \& Langoni H. 2018. [Quality parameters of bovine milk from family farms.] Parâmetros de qualidade do leite bovino em propriedades de agricultura familiar. Pesquisa Veterinária Brasileira 38(4):573-578. Departamento de Higiene Veterinária e Saúde Pública, Faculdade de Medicina Veterinária e Zootecnia, Universidade Estadual Paulista "Julio de Mesquita Filho", Distrito de Rubião Júnior, Botucatu, SP 18618-970, Brazil. E-mail: hlangoni@fmvz.unesp.br

Family operated dairies have contributed to increase milk production and can be considered important in the milk production chain. Hygiene in the productive process must be the major focus to assure greater milk quality and production. The quality of milk from cows in family farms in the city of Bofete/SP was monitored before and after the establishment of control measures. Twenty-one dairy family farms, selected for convenience, were evaluated. After the initial period of 13 collections for SCC and TBC monitoring, farmers of the two groups (G1 and G2) received technical guidance about mastitis and milk quality during a day of field activity. G1 farmers, besides these activities, received intervention in the adopted management by means of technical visit and individual guidance as to adequate milking manner and hygienic milk production. Then, new fortnight collections $(n=12)$ were performed, as previously, of a set of milk samples from each farm and both groups, as well as from the community tank. Climate variables were considered, such as rainfall, temperature and relative humidity. There was a variation in the results of each collection for both SCC $/ \mathrm{mL}$ milk and TBC/mL milk in the two periods. As to SCC in G1, there was a statistically significant decrease $(\mathrm{P}<0.02)$, while for TBC there was a slight increase, rather lower compared to the median value, which was $381 \times 10^{3} \mathrm{CFU} / \mathrm{mL}$ milk in G2. The median results of SCC $/ \mathrm{mL}$ milk and TBC/mL milk from the community tank were greater in the two stages (periods), but much superior for TBC. Analysis of the climate variables evidenced an increase in the medians for all three evaluated parameters. The correlation between these variables and milk quality did not show differences for $\log _{10}$ of SCC and TBC. It can be concluded that the milking management hygiene was precarious.
\end{abstract}

INDEX TERMS: Milk quality indicators, cattle, family farms, sanitary education, SCC, TBC.

\footnotetext{
${ }^{1}$ Recebido em 7 de abril de 2017.

Aceito para publicação em 18 de abril de 2017.

${ }^{2}$ Núcleo de Pesquisa em Mastites (Nupemas), Departamento de Higiene Veterinária e Saúde Pública, Faculdade de Medicina Veterinária e Zootecnia (FMVZ), Universidade Estadual Paulista "Julio de Mesquita Filho" (Unesp), Distrito de Rubião Júnior, Botucatu, SP 18618-970, Brasil.

${ }^{3}$ Pós-Graduando Mestrando, Departamento de Higiene Veterinária e Saúde Pública, Faculdade de Medicina Veterinária e Zootecnia (FMVZ), Universidade Estadual Paulista "Julio de Mesquita Filho" (Unesp), Distrito de Rubião Júnior, Botucatu, SP 18618-970.

4 Núcleo de Pesquisa em Mastites (Nupemas), Departamento de Higiene Veterinária e Saúde Pública, Faculdade de Medicina Veterinária e Zootecnia (FMVZ), Universidade Estadual Paulista "Julio de Mesquita Filho" (Unesp), Distrito de Rubião Júnior, Botucatu, SP 18618-970. *Autor de correspondência: hlangoni@fmvz.unesp.br
}

RESUMO.- Propriedades da agricultura familiar tem contribuído para aumentar a produção leiteira, e podem ser considerados importantes para cadeia produtiva do leite. A higiene no processo produtivo deve ser o foco principal para garantir maior produção e qualidade do leite. Monitorou-se a qualidade do leite de vacas, em propriedades da agricultura familiar, no município de Bofete/SP, antes e após a adoção de medidas de controle. Avaliaram-se 21 propriedades, selecionadas por conveniência. Após período inicial de 13 coletas para monitoramento de CCS e CBT, os proprietários dos dois grupos (G1 e G2) receberam orientações técnicas sobre mastite e qualidade do leite, em atividade de dia de campo. Os proprietários do G1 além dessas atividades receberam 
intervenção no manejo utilizado, com visita técnica, e orientações individuais quanto à maneira adequada de ordenha e obtenção higiênica do leite. Posteriormente foram realizadas novas coletas quinzenais $(n=12)$ como anteriormente, de amostras de leite de conjunto, de cada propriedade dos dois grupos, bem como do tanque comunitário. Foram consideradas variáveis climáticas como precipitação, temperatura e umidade relativa do ar. Observou-se uma variação dos resultados de cada coleta tanto para CCS $/ \mathrm{mL}$ de leite quanto para CBT $/ \mathrm{mL}$ de leite, nos dois períodos. Quanto a CCS no G1 houve uma diminuição significativa $(\mathrm{P}<0,02)$, enquanto que para CBT houve um ligeiro aumento, bem menor, quando comparado ao valor mediano que foi de $381 \times 10^{3} \mathrm{UFC} / \mathrm{mL}$ de leite no G2. Os resultados medianos de CCS/mL de leite e de CBT $/ \mathrm{mL}$ de leite do tanque comunitário foram mais elevados nas duas fases (períodos), entretanto muito superior para CBT. A análise das variáveis climáticas evidenciou aumento das medianas nos três parâmetros avaliados. A correlação entre essas variáveis e qualidade do leite, não mostrou diferenças para o $\log _{10}$ da CCS e CBT. Pode-se concluir pela higiene precária no manejo de ordenha.

TERMOS DE INDEXAÇÃO: Indicadores de qualidade do leite, bovinos, propriedade familiar, educação sanitária, CCS, CBT.

\section{INTRODUÇ̃̃o}

O leite é considerado um alimento completo e necessário em todas as fases do desenvolvimento humano, desde o nascimento, a mais tenra idade, até a velhice. Sua qualidade é influenciada por uma série de fatores, dentre os quais o manejo dos animais, a alimentação e a sanidade das glândulas mamárias (Domingues \& Langoni 2001).

Durante o processo de ordenha, a contaminação bacteriana pode ser proveniente de sujidades do úbere, mãos do ordenhador, dos equipamentos de ordenha (como as teteiras) e, ainda, de tambores e baldes mal higienizados. Nesses casos a contaminação maior é por micro-organismos ambientais como coliformes, particularmente Escherichia coli (Cardoso \& Araújo 2004). Por outro lado, a contaminação pode ser devido à mastite, enfermidade multifatorial, de ampla etiologia (Langoni et al. 1998) podendo ser causada tanto por patógenos contagiosos como ambientais.

Os aspectos de qualidade do leite devem ser considerados independentes do sistema de produção, tamanho das propriedades e nível sócio econômico do produtor, pois a principal prática para se obter produto de qualidade é a higiene o que parece ser compreensível, e possível de ser praticada por todos aqueles que se interessam pela própria saúde, bem como dos consumidores tanto de leite como de seus derivados. Sabidamente o leite pode carrear inúmeros micro-organismos causadores de diferentes enfermidades para os humanos (Santana et al. 2001, Vasconcelos \& Ito 2011, Langoni 2013).

A idade, raça, manejo, condições climáticas e patógenos envolvidos na infecção são variáreis entre as propriedades, sendo importante a avaliação dos fatores de risco individualmente para que se estabeleça um programa de controle, com monitoramento da qualidade do leite (Langoni 2013).

Há diferenças no manejo sanitário entre as propriedades e produtores de leite, fato que interfere na qualidade final do produto obtido na ordenha de vacas sadias, que é entregue ao laticínio. De acordo com esse manejo, é possível também avaliar os aspectos de produtividade, já que a ocorrência de mastites diminui a produção leiteira (Callefe \& Langoni 2015). De acordo com o manejo estabelecido pode haver uma maior ocorrência de mastites contagiosas ou ambientais (Domingues \& Langoni 2001)

Os testes empregados para avaliar a qualidade do leite fluido constituem normas regulamentares em todos os países, havendo pequena variação entre os parâmetros avaliados e/ou tipos de testes empregados. São avaliadas as características físico-químicas e sensoriais como sabor, odor, e definidos parâmetros da contagem bacteriana total (CBT), ausência de micro-organismos patogênicos, contagem de células somáticas (CCS), ausência de conservantes químicos e de resíduos antimicrobianos, pesticidas ou outros produtos considerados nocivos para humanos (Brito \& Brito 2004).

No Brasil, a IN-62 publicada em dezembro de 2011, regulamenta a produção, identificação, qualidade, coleta e transporte do leite tipo A, leite cru refrigerado e leite pasteurizado. Os parâmetros para CCS e CBT foram escalonados para as diferentes regiões do país e por períodos (Brasil 2011).

0 MAPA estabeleceu critérios de padronização do leite produzido e oferecido para consumo no país por meio de portarias como a IN-51 substituída pela IN-62 de 2011 (Brasil 2011). No momento das coletas para a realização do presente estudo, os valores máximos para o leite cru refrigerado era de 500.000 céls/mL para CCS e de 300.000 UFC/mL, para a CBT.

As células somáticas estão presentes no leite e são constituídas pelas células de descamação do epitélio secretor, e pelos leucócitos que são as células de defesa do organismo, provenientes da corrente sanguínea, incluindo os monócitos, linfócitos, neutrófilos e macrófagos (Schukken et al. 2003). A elevação no número dessas células é um indicador de mastite subclínica (Brito \& Brito 2004).

A CBT refere-se a contagem do número total de micro-organismos aeróbicos, dando um resultado em determinada quantidade de bactérias ou unidades formadoras de colônias, permitindo avaliar a qualidade do leite desde o momento de ordenha até sua estocagem (Brito \& Brito 2004).

Em 2006, de acordo com o censo agropecuário do Instituto Brasileiro de Geografia e Estatística (IBGE), a contribuição da agricultura familiar foi expressiva e alcançou 58\% no que se refere à produção nacional de leite (IBGE 2006).

Considerando a necessidade do controle da mastite e melhoria da qualidade do leite bovino nacional, da contribuição dos produtores da agricultura familiar, do baixo acesso à tecnologia e informação sobre qualidade do leite, e dos riscos para a Saúde Pública; realizou-se o presente estudo com objetivo de avaliar a qualidade do leite em propriedades da agricultura familiar, que utilizam um tanque de expansão comunitário instalado na Casa da Agricultura de Bofete, SP, antes e após a adoção de orientações técnicas, para o controle de mastites e obtenção higiênica do leite.

\section{MATERIAL E MÉTODOS}

Propriedades. Foram utilizadas pequenas propriedades leiteiras da agricultura familiar. 0 tamanho das propriedades que fizeram parte da pesquisa tinha em média 29 hectares, sendo a menor com 3,5 hectares e a maior, 120 hectares. Quanto à produção média diária de leite, era de 40 litros/dia por propriedade. A menor produção era de 10 litros e a maior de 100 litros/dia. Os produtores de leite 
foram selecionados, por conveniência, e pelo interesse em colaborar no estudo, e que utilizam o tanque comunitário instalado na Casa da Agricultura de Bofete, município do interior paulista.

Formação dos grupos. Foram selecionados inicialmente 30 produtores, de acordo com o interesse de adesão ao projeto constituindo-se dois grupos, G1 e G2. Cada grupo foi composto por 15 produtores, definidos pela constância na produção de leite e na utilização do tanque comunitário para refrigeração do leite produzido diariamente.

Após período inicial de 13 coletas, os proprietários dos dois grupos receberam orientações técnicas, visando controle de mastites e a obtenção higiênica do leite. As orientações foram transmitidas por meio de um dia de campo que se consistiu em uma palestra com o tema "Importância da obtenção higiênica do leite, mastites e seu controle”. Incluiu-se parte prática com orientações sobre limpeza, higienização e desinfecção de tetos previamente a ordenha, como lavagem e secagem de tetos, utilização de pré e pós-dipping, além da coleta de leite para exames de CCS, CBT, e exames microbiológicos com o objetivo de isolamento de micro-organismos causadores de mastite.

Além das atividades do dia de campo, os proprietários do G1 receberam intervenção no manejo adotado, pela realização de visita técnica nas propriedades, e orientações individuais quanto à maneira adequada de ordenha e obtenção higiênica do leite. Já os proprietários do G2 (grupo controle) não receberam orientação e intervenção no manejo nas propriedades. Posteriormente foram realizadas novas coletas de amostras de leite quinzenalmente $(n=12)$, de amostras de leite conjunto, de cada propriedade dos dois grupos, bem como do tanque comunitário.

Ao final do projeto, o G1 se manteve com 11 produtores, pois quatro proprietários não entregaram o leite com regularidade, e desta forma para não prejudicar a análise dos resultados optou-se por excluí-los do projeto. 0 grupo controle (G2), inicialmente também composto por 15 produtores foram, selecionados de acordo com o mesmo critério para a formação do G1. Em ambos os grupos as propriedades foram enumeradas de um a quinze. Os proprietários do G2 não receberam intervenção por meio da realização de visita técnica, mantendo a rotina de ordenha habitual praticada na propriedade. No decorrer do projeto cinco produtores do G2 também não mostraram regularidade na entrega de leite, sendo excluídos do estudo, permanecendo com dez produtores.

Coletas de amostras para CCS e CBT. Os produtores entregavam o leite diariamente no tanque comunitário, no período da manhã. As coletas foram realizadas com auxílio de concha metálica esterilizada, após a homogeneização individualmente, do tambor de cada produtor. Coletou-se ao redor de $50 \mathrm{~mL}$ de leite, em frascos contendo duas pastilhas de bronopol para CCS, e também ao redor de $50 \mathrm{~mL}$ em frascos estéreis contendo quatro pastilhas de azidiol para a avaliação da CBT. Em seguida as amostras foram enviadas em até 2 dias ao laboratório da Rede Brasileira de Qualidade do Leite (RBQL), na Clínica do Leite (ESALQ, Piracicaba), acondicionadas em caixas de isopor e processadas por citometria de fluxo. Além das amostras individuais de cada propriedade, foram coletadas amostras do leite do conjunto de todos os produtores do tanque comunitário, após homogeneização, tanto para a CCS como CBT, consideradas como amostras de conjunto, para se avaliar a qualidade do leite total depositado no tanque de refrigeração, já que outros produtores utilizavam o tanque comunitário. As amostras de leite foram coletadas, quinzenalmente, durante o período de agosto de 2014 a junho de 2015.

Análise estatística. As distribuições da CCS e CBT foram avaliadas e transformadas em escala logarítmica. Estatísticas descritivas da
CCS e CBT foram produzidas nos Grupos G1 e G2 (propriedades com e sem orientações), fases (antes e após orientação), com intervalo entre coletas de 15 dias. Uma análise de variância foi realizada para comparação da CCS e CBT do leite do tanque comunitário entre as fases do estudo. A correlação simples entre a CCS e a CBT, e os parâmetros climáticos (precipitação, temperatura e umidade relativa) foi realizada em cada fase do estudo para identificar e quantificar possíveis associações entre estas variáveis. Para comparação da precipitação, temperatura e umidade relativa entre os grupos dentro de cada fase do estudo, e entre um mesmo grupo (ou tanque comunitário) em fases distintas foram utilizados os testes de Wilcoxon para amostras independentes e amostras pareadas, respectivamente.

Modelos mistos de medidas repetidas foram desenvolvidos para realização das análises multivariadas da CCS e CBT em função do grupo, fase, precipitação, temperatura e umidade relativa. Termos de interação entre as variáveis explicativas foram incluídos no modelo e, as variáveis climáticas e os termos de interação permaneceram no mesmo caso significantes. Uma análise de variância foi realizada para comparação da CCS e CBT do leite do tanque comunitário entre as fases do estudo, oferecendo-se ao modelo os parâmetros climáticos como co-variáveis quantitativas. A análise estatística foi realizada com o software estatístico SAS 9.3 em nível de significância de 0,05.

\section{RESULTADOS E DISCUSSÃO}

As características das propriedades do Grupo 1 e do Grupo 2 identificadas no início do estudo são semelhantes. Predomina a ordenha manual nos dois grupos. A lavagem dos tetos não é realizada por $72 \%$ dos produtores de leite do Grupo 1 e $50 \%$ do Grupo 2.0 pré e o pós-dipping não são realizados em nenhuma das propriedades. Apenas 18\% dos produtores do Grupo 1 e 10\% dos produtores do Grupo 2 realizavam California Mastitis Test (CMT), conforme apresentado no Quadro 1.

A análise da CCS/mL e da CBT/mL de leite individual por produtor (G1 e G2) nas coletas de leite, antes e após as atividades de orientação realizadas no dia de campo e pelo acompanhamento técnico após a orientação (G1), pode ser observada no Quadro 2.

Verifica-se uma variação dos resultados de cada coleta tanto para CCS/mL de leite quanto para CBT $/ \mathrm{mL}$ de leite, nos períodos pré e pós-orientação. Este fato é esperado considerando-se os aspectos ambientais, como índice pluviométrico, principalmente quando se avalia a CBT $/ \mathrm{mL}$ de leite. 0 importante é a conscientização dos produtores para manutenção dentro dos parâmetros de qualidade do leite, que no momento do estudo de acordo com IN 62 era de $500.000 \mathrm{~mL}$ de leite para CCS e de $300.000 \mathrm{CBT} / \mathrm{mL}$ de leite (Brasil 2011).

Os resultados da CCS e CBT/mL de leite do tanque de expansão comunitário, das amostras de leite obtidas nos mesmos momentos para a avaliação do leite de conjunto produzido em cada propriedade, estão sumarizados no Quadro 3.

Verifica-se que em $84,6 \%$ do total de coletas realizadas, do tanque de expansão, estavam de acordo com as normas vigentes e atendiam a IN 62 quanto a CCS/mL de leite. Quanto a CBT/mL de leite $100 \%$ das coletas estavam fora dos parâmetros estabelecidos de 300.000 UFC/mL de leite (Brasil 2011). Ressalta-se que além dos proprietários envolvidos no presente estudo, outros utilizavam no mesmo tanque, totalizando 33 produtores, fato que explica a variação encontrada principalmente com relação à CCS/mL de leite. 
Quadro 1. Caracterização das propriedades. Botucatu/SP, 2016

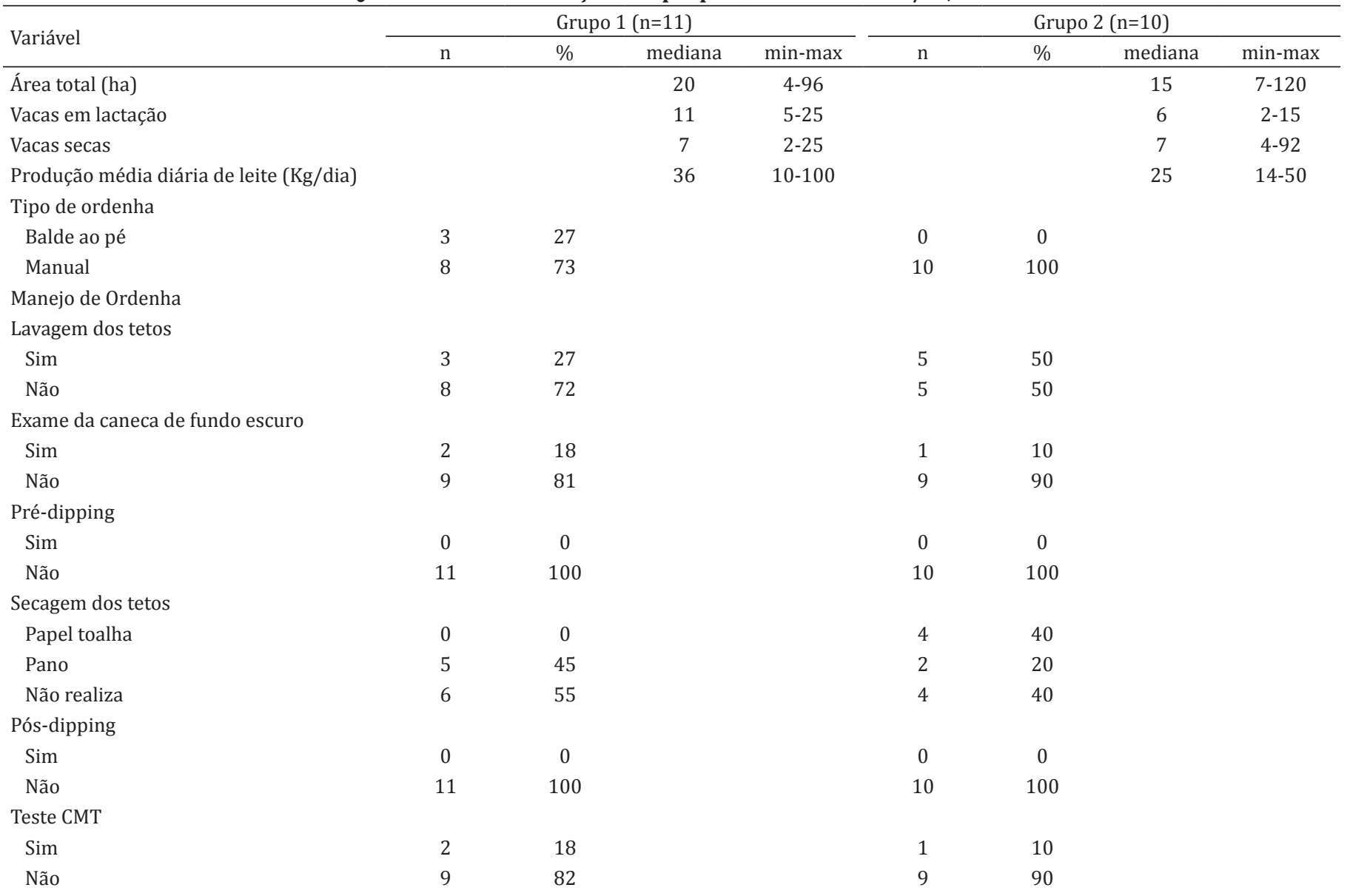

Quadro 2. Resultados das medianas da CCS e CBT de leite individual de vacas, nas propriedades dos G1 e G2 antes e após a orientação técnica. Botucatu/SP, 2016

\begin{tabular}{|c|c|c|c|c|c|}
\hline \multirow{2}{*}{\multicolumn{2}{|c|}{ Propriedades }} & \multicolumn{2}{|c|}{ Pré-orientação } & \multicolumn{2}{|c|}{ Pós-orientação } \\
\hline & & \multirow{2}{*}{$\begin{array}{l}\mathrm{CCS} / \mathrm{mL} \\
219.000\end{array}$} & \multirow{2}{*}{$\frac{\mathrm{CBT}(\mathrm{UFC} / \mathrm{mL})}{127.500}$} & \multirow{2}{*}{$\begin{array}{l}\mathrm{CCS} / \mathrm{mL} \\
185.000\end{array}$} & \multirow{2}{*}{$\frac{\text { CBT (UFC/mL) }}{347.000}$} \\
\hline Grupo 1 & 1 & & & & \\
\hline & 2 & 438.000 & 321.500 & 194.500 & 148.000 \\
\hline & 3 & 261.000 & 590.000 & 125.500 & 641.500 \\
\hline & 4 & 259.000 & 197.000 & 204.000 & 194.500 \\
\hline & 5 & 518.000 & 199.000 & 250.500 & 265.000 \\
\hline & 6 & 174.000 & 176.000 & 239.000 & 337.000 \\
\hline & 7 & 137.000 & 201.500 & 111.000 & 223.000 \\
\hline & 8 & 140.000 & 296.000 & 120.000 & 127.000 \\
\hline & 9 & 205.000 & 555.000 & 131.000 & 110.000 \\
\hline & 10 & 310.000 & $\mathrm{NC}$ & 75.000 & 148.000 \\
\hline & 11 & 172.000 & 809.000 & 91.000 & 393.000 \\
\hline \multirow[t]{10}{*}{ Grupo 2} & 1 & 215.000 & 758.000 & 115.500 & 479.500 \\
\hline & 2 & 239.000 & 19.000 & 152.500 & 490.000 \\
\hline & 3 & 291.000 & 282.000 & 159.500 & 342.000 \\
\hline & 4 & 214.500 & 135.000 & 161.000 & 331.500 \\
\hline & 5 & 268.000 & 577.000 & 201.500 & 3.153 .500 \\
\hline & 6 & 223.000 & 1.273 .000 & 180.000 & 4.291 .500 \\
\hline & 7 & 243.000 & 459.000 & 154.000 & 717.500 \\
\hline & 8 & 209.000 & 33.000 & 164.500 & 130.000 \\
\hline & 9 & 242.000 & 241.500 & 58.500 & 439.500 \\
\hline & 10 & 204.500 & NC & 80.000 & 130.000 \\
\hline
\end{tabular}

$\mathrm{NC}=$ não coletado, $\mathrm{CCS}$ = contagem de células somáticas, CBT = contagem bacteriana total, UFC = unidade formadora de colônia, G1 = grupo com orientação de prática de ordenha, G2 = grupo sem orientação de prática de ordenha. 
Os resultados medianos referentes à $\mathrm{CCS} / \mathrm{mL}$ de leite e $\mathrm{CBT} / \mathrm{mL}$ de leite para os produtores dos Grupos 1 e 2 bem como do tanque de expansão, estão apresentados no Quadro 4.

Quanto a CCS no G1 houve uma diminuição significante estatisticamente $(\mathrm{P}<0,02)$, enquanto que para CBT aconteceu o contrário, mostrando um ligeiro aumento, entretanto bem menor, quando se compara ao G2 cujo valor mediano foi de $381 \times 10^{3} \mathrm{UFC} / \mathrm{mL}$ de leite na fase final das coletas. Quanto aos resultados medianos tanto para $\mathrm{CCS} / \mathrm{mL}$ de leite como para $\mathrm{CBT} / \mathrm{mL}$ de leite do tanque comunitário, os valores foram mais elevados nas duas fases (pré e pós-orientação), entretanto muito superior para CBT. Esse fato já era de se esperar uma vez que essas variáveis no caso de tanque comunitário são mais difíceis de serem controladas, na medida em que há mistura de leite de outros produtores que não fizeram parte do estudo.

Com relação aos valores medianos da CCS/mL de leite pode-se observar que em nenhuma das fases foram excedidos os limites indicados pela IN 62, no momento do estudo. No entanto, a mediana da CBT do tanque comunitário apresentou valores superiores ao recomendado, nas duas fases pesquisadas. Já no Grupo 2, sem orientação, os valores exigidos para época foram superiores, somente na segunda fase do estudo.

A análise das variáveis climáticas evidencia um aumento das medianas de precipitação, temperatura e umidade relativa do ar quando se compara os momentos pré e pós-orientação de acordo com o Quadro 5, no entanto, a análise da correlação entre as variáveis climáticas e qualidade do leite, não mostrou diferenças para o $\log ^{10}$ da CCS, e da CBT.

Vargas et al. (2013) ao analisar 1.541 rebanhos, pertencentes a 15 municípios, localizados na região Sul do Brasil, não encontraram correlação significativa entre o logaritmo natural da CBT normal e as variáveis climáticas (temperatura ambiente, umidade relativa do ar e precipitação pluviométrica). Já Bueno et al. (2008) reportaram ausência de correlação $(\mathrm{P}>0,05)$ entre a CBT e a temperatura ambiente em 16.491 amostras de leite obtidas em tanques de refrigeração de uso individual, no estado de Goiás. Por outro lado, estes mesmos autores encontraram correlação significativa entre CBT e umidade relativa do ar $(\mathrm{r}=0,76 ; \mathrm{P}<0,001)$.

Resultado semelhante foi encontrado por Nakamura et al. (2012) ao analisarem a correlação entre variáveis climáticas e qualidade do leite em amostras obtidas de tanques de resfriamento de três regiões do Paraná. Diferente dos outros parâmetros estudados, os $\log ^{10}$ da CCS, e da CBT não foram influenciados pela temperatura, no entanto, encontraram correlação significativa, porém fraca entre precipitação, e CCS $(r=0,102 ; \mathrm{p}<0,05)$ e CBT $(\mathrm{r}=0,232 ; \mathrm{p}<0,05)$ e umidade relativa, e CCS ( $r=0,316 ; p<0,01)$, e CBT $(R=0,262 ; p<0,01)$.

Os resultados obtidos no presente estudo, principalmente quanto à $\mathrm{CBT} / \mathrm{mL}$ de leite, representam a higiene precária no manejo de ordenha nas propriedades participantes do estudo, pois no início da pesquisa nenhum dos proprietários realizava pré-dipping, e apenas três desprezavam os três primeiros jatos de leite na caneca de fundo preto. Essas práticas diminuem a carga bacteriana do leite, o que reflete em menores concentrações de CBT/mL de leite (Vallin et al. 2009, Santos 2012, Langoni 2013, Callefe \& Langoni 2015).

A localização das propriedades, tipo de solo, aspectos topográficos, influência de ventos, a altitude, entre outros aspectos, podem influenciar os resultados referentes às variáveis pesquisadas, enfatizando-se que muitas vezes devem ser avaliadas essas características em programas de controle de mastites, visando-se a melhor qualidade do leite oferecido para o consumo (Langoni 2013).

Para a produção de leite há necessidade de aplicação de conceitos de higiene e de sanidade animal, dependentes de boa orientação de técnicos especializados. Não há outra forma de incluir o pequeno produtor na cadeia produtiva do leite,

Quadro 3. Resultados da CCS e CBT/mL de leite do tanque comunitário, das amostras de leite, independente da propriedade, avaliadas nas varias coletas, antes e após orientação técnica. Botucatu/SP, 2016

\begin{tabular}{|c|c|c|c|c|}
\hline \multirow[b]{2}{*}{ Propriedades } & \multicolumn{2}{|c|}{ Pré-orientação } & \multicolumn{2}{|c|}{ Pós-orientação } \\
\hline & $\mathrm{CCS} / \mathrm{mL}$ & $\begin{array}{c}\text { CBT } \\
\text { (UFC/mL) } \\
\end{array}$ & $\mathrm{CCS} / \mathrm{mL}$ & $\begin{array}{c}\text { CBT } \\
\text { (UFC/mL) }\end{array}$ \\
\hline $1^{\mathrm{a}}$ & 396.000 & 1.104 .000 & 315.000 & 2.426 .000 \\
\hline $2^{\mathrm{a}}$ & 665.000 & 2.329 .000 & 349.000 & 1.513 .000 \\
\hline $3^{\mathrm{a}}$ & 380.000 & 789.000 & 455.000 & 6.475 .000 \\
\hline $4^{\mathrm{a}}$ & 518.000 & $\mathrm{NC}$ & 268.000 & 5.848 .000 \\
\hline $5^{\mathrm{a}}$ & 349.000 & 1.292 .000 & 430.000 & 2.853 .000 \\
\hline $6^{\mathrm{a}}$ & 387.000 & 1.085 .000 & 218.000 & 5.006 .000 \\
\hline $7^{\mathrm{a}}$ & 236.000 & 620.000 & 1.457 .000 & 1.153 .000 \\
\hline $8^{\mathrm{a}}$ & 281.000 & 1.814 .000 & 793.000 & 310.000 \\
\hline $9 \underline{a}$ & 321.000 & 1.099 .000 & 37.000 & 1.479 .000 \\
\hline $10^{\mathrm{a}}$ & 403.000 & $\mathrm{NC}$ & 67.000 & 310.000 \\
\hline $11^{\mathrm{a}}$ & 400.000 & 4.871 .000 & 115.000 & 1.075 .000 \\
\hline $12^{\mathrm{a}}$ & 264.000 & 1.759 .000 & 1.235 .000 & 1.235 .000 \\
\hline $13^{\mathrm{a}}$ & 359.000 & 850.000 & $\mathrm{NC}$ & $\mathrm{NC}$ \\
\hline Mediana & 380.000 & 1.292 .000 & 332.000 & 1.496 .000 \\
\hline
\end{tabular}

$\overline{\mathrm{NC}}=$ não coletado, $\mathrm{CCS}=$ contagem de células somáticas, $\mathrm{CBT}=$ contagem bacteriana total, UFC = unidade formadora de colônia.

Quadro 4. Resultados das medianas da CCS/mL de leite e $\mathrm{CBT} / \mathrm{mL}$ de leite nas amostras de leite dos produtores dos G1 e G2 nas fases de pré-orientação e pós-orientação, bem como do tanque comunitário. Botucatu/SP, 2016

\begin{tabular}{cccccc}
\hline \multirow{2}{*}{ Grupos } & \multicolumn{2}{c}{ Pré-orientação (G1e G2) } & & \multicolumn{2}{c}{ Pós-orientação (G1) } \\
\cline { 2 - 3 } \cline { 5 - 6 } & $\mathrm{CCS} / \mathrm{mL}$ & $\mathrm{CBT} / \mathrm{mL}$ & & $\mathrm{CCS} / \mathrm{mL}$ & $\mathrm{CBT} / \mathrm{mL}$ \\
\hline Grupo1 & $230 \times 10^{3 \mathrm{a}}$ & $192 \times 10^{3}$ & & $159 \times 10^{3 \mathrm{~b}}$ & $228 \times 10^{3}$ \\
Grupo 2 & $219 \times 10^{3}$ & $224 \times 10^{3}$ & & $155 \times 10^{3}$ & $381 \times 10^{3}$ \\
Tanque & $368 \times 10^{3}$ & $1.424 \times 10^{3}$ & & $229 \times 10^{3}$ & $1.658 \times 10^{3}$
\end{tabular}

Letras minúsculas indicam diferença estatisticamente significante entre as fases em um mesmo grupo (CCS Grupo 1, $P=0,019$; CCS Grupo 2, $P=0,056$; CBT Grupo 1, $P=0,819$; CBT Grupo 2, $P=0,094$ ).

Quadro 5. Resultados das medianas das variáveis climáticas nas fases de pré-orientação e pós-orientação. Botucatu/SP, 2016

\begin{tabular}{ccc}
\hline Variáveis climáticas & Pré-orientação & Pós-orientação \\
\hline Precipitação $(\mathrm{mm})$ & 0,20 & 0,30 \\
Temperatura $\left({ }^{\circ} \mathrm{C}\right)$ & 21,03 & 22,06 \\
Umidade relativa do ar $(\%)$ & 71,42 & 75,83
\end{tabular}


se não houver estímulo e o oferecimento de apoio técnico de forma regular e constante. Desta forma sugere-se adoção de políticas públicas voltadas aos pequenos produtores de leite, da agricultura familiar, fixando-os nas propriedades, estimulando-os para incrementar a produção de leite, melhorando a sua qualidade, oferecendo-se condições de sobrevivência em função das atividades que desenvolvem.

\section{CONCLUSÕES}

Houve redução da CCS/mL de leite no G1 significante estatisticamente $(p=0,02)$, indicando que as orientações transmitidas repercutiram positivamente na adoção de medidas que reduziram a celularidade dos rebanhos, reforçando a importância da educação sanitária, principalmente para os produtores de leite da agricultura familiar, normalmente com menor poder aquisitivo.

Para CBT/mL de leite no G1, ocorreu um ligeiro aumento, entretanto bem menor quando comparado ao G2. A elevada $\mathrm{CBT} / \mathrm{mL}$ do leite de conjunto, deve ser consequência da utilização do mesmo tanque por produtores de leite que não participaram do estudo.

A análise das variáveis climáticas evidencia um aumento das medianas de precipitação, temperatura e umidade relativa do ar quando se compara os momentos pré e pós-orientação, no entanto, a análise da correlação entre as variáveis climáticas e qualidade do leite, não mostrou diferenças para o $\log ^{10} \mathrm{da}$ CCS, e da CBT.

Comissão de Ética.- Aprovado pela Câmara de Ética em Experimentação Animal (Protocolo no 23/2009-CEEA).

\section{REFERÊNCIAS}

Brasil 2011. Instrução normativa no 62, Gabinete do Ministro, Ministério da Agricultura, Pecuária e Abastecimento, Brasília, 29 dez. 2011.

Brito M.A.V.P. \& Brito J.R.F. 2004. Qualidade do leite, p.61-74. In: Campos O.F. \& Miranda J.E.C. (Eds), Gado de Leite: o produtor pergunta, a Embrapa responde. $2^{\underline{a}}$ ed. Embrapa Informação Tecnológica, Brasília, DF. 239p.

Bueno V.F.F., Mesquita A.J., Oliveira A.N., Nicolau E.S. \& Neves R.B.S. 2008. Contagem bacteriana total do leite: relação com a composição centesimal e período do ano no Estado de Goiás. Revta Bras. Ciênc. Vet. 15(1):40-44. http://dx.doi.org/10.4322/rbcv.2014.194.

Callefe J.L.R. \& Langoni H. 2015. Qualidade do leite: uma meta a ser atingida. Vet. Zootec. 22(2):151-162.
Cardoso L. \& Araújo W.M.C. 2004. Parâmetros de qualidade em queijos comercializados no Distrito Federal, no período de 1997-2001. Revta Hig. Alim. 18(123):49-53.

Domingues P.F. \& Langoni H. 2001. Manejo Sanitário Animal. Editora de Publicações Biomédicas (EPUB), Rio de Janeiro. 209p.

IBGE 2006. Agricultura familiar: primeiros resultados, 2006. Censo Agropecuário. Instituto Brasileiro de Geografia e Estatística. Disponível em <http://biblioteca.ibge.gov.br/visualizacao/periodicos/50/agro_2006_ agricultura_familiar.pdf> Acesso em 14 jun. 2016.

Langoni H. 2013. Qualidade do leite: utopia sem um programa sério de monitoramento da ocorrência de mastite bovina. Pesq. Vet. Bras. 33(5):620626. http://dx.doi.org/10.1590/S0100-736X2013000500012.

Langoni H., Silva A.V., Cabral K.G. \& Domingues P.F. 1998. Aspectos etiológicos na mastite bovina: flora bacteriana aeróbica. Revta Bras. Med. Vet. 20(5):204-209.

Nakamura A.Y., Alberton L.R., Otutumi L.K., Donadel D., Turci R.C., Agostinis R.O. \& Caetano I.C.S. 2012. Correlação entre as variáveis climáticas e a qualidade do leite de amostras obtidas em três regiões do estado do Paraná. Arq. Ciênc. Vet. Zool. Unipar 15(2):103-108. https://doi.org/10.25110/ arqvet.v15i2.2012.4211.

Santana E.H.W., Beloti V., Barros M.D.A.F., Moraes L.B., Gusmão V.V. \& Pereira M.S. 2001. Contaminação do leite em diferentes pontos do processo de produção. I. Microrganismos aeróbios mesófilos e psicrotróficos. Semina, Ciênc. Agrárias 22(2):145-154. http://dx.doi.org/10.5433/16790359.2001v22n2p145.

Santos M.V. 2012. Cuidados com higiene melhoram contagem bacteriana total. Mundo Leite 55:13-16.

Schukken Y.H., Wilson D.J., Welcome F., Garrison-Tikofsky L. \& Gonzalez R.N. 2003. Monitoring udder health and milk quality using somatic cell counts. Vet. Res. 34(5):579-596. http://dx.doi.org/10.1051/vetres:2003028. PMid:14556696.

Vallin V.M., Beloti V., Battaglini A.P.P., Tamanini R., Fagnani R., Angela H.L. \& Silva L.C.C. 2009. Melhoria da qualidade do leite a partir da implantação de boas práticas de higiene na ordenha em 19 municípios da região central do Paraná. Semina, Ciênc. Agrárias 30(1):181-188. http://dx.doi. org/10.5433/1679-0359.2009v30n1p181.

Vargas D.P., Nörnberg J.L., Mello R.O., Sheibler R.B., Milani M.P. \& Mello F.C.B. 2013. Correlações entre contagem bacteriana total e parâmetros de qualidade do leite. Revta Bras. Ciênc. Vet. 20(4):241-247. https://doi. org/10.22409/rbcv.v20i4.334.

Vasconcelos S.A. \& Ito F.H. 2011. Principais zoonoses transmitidas pelo leite: atualização. Revta Educ. Cont. 9(1):32-37. Disponível em <http://revistas. bvs-vet.org.br/recmvz/article/view/388/359> Acesso em 20 jan. 2016. 